\title{
MONITORING OF SHAFT EXCAVATIONS IN CLAY
}

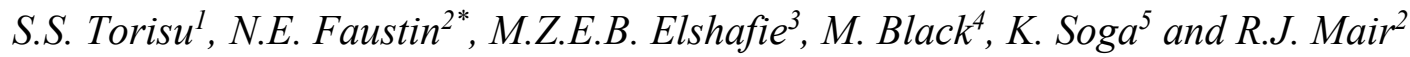 \\ ${ }^{1}$ Design Department, Obayashi Corporation, 2-15-2, Konan, Minato, Tokyo, Japan \\ ${ }^{2}$ Department of Engineering University of Cambridge, Trumpington Street, Cambridge, CB2 1PZ, UK \\ ${ }^{3}$ Department of Civil and Architectural Engineering, Qatar University, PO Box 2713 Doha, Qatar \\ ${ }^{4}$ Crossrail Limited, London, UK \\ ${ }^{5}$ Department of Civil and Environmental Engineering, University of California, Berkeley, 760 Davis Hall, 94720- \\ 1710 USA \\ * Corresponding author
}

\begin{abstract}
Field observations of infrastructure performance, during and following construction, are vital for efficient design of infrastructure in subsequent projects. Fibre optic sensing technology offers considerable benefits because it provides a continuous measurement profile along its length whereas conventional monitoring instrumentation, such as strain gauges, only offer discrete measurements. This paper describes two case studies in which fibre optic sensors were used to monitor the bending of heavily reinforced diaphragm walls installed during the construction of the Elizabeth Line (formerly called Crossrail), in London, UK. The first case study was a $30 \mathrm{~m}$ diameter, $44 \mathrm{~m}$ deep circular shaft constructed to launch the tunnel boring machines. The second case study was an almost rectangular ventilation and access shaft, $65 \mathrm{~m}$ in length, $16 \mathrm{~m}$ to $18 \mathrm{~m}$ wide and up to $36 \mathrm{~m}$ deep. The fibre optic sensing system was secured to the reinforcement cages of the diaphragm wall panels to measure mechanical and thermal strains during excavation. This allowed the effect of temperature changes to be accounted for. Field measurements were taken at regular intervals during excavation of both shafts. The two case study shafts, details of the fibre optic sensing system and some of the strain measurements are presented in this paper. The measurements demonstrate the effectiveness of fibre optics for structural monitoring of diaphragm wall shaft linings. They also confirm that fibre optic monitoring has an important role to play in performance-based design - in optimising and improving future designs.
\end{abstract}

\section{Notation}

$\alpha_{\alpha}$ - Temperature-induced apparent strain of Brillouin frequency shift

$\alpha_{b}$ - Thermal expansion coefficient of temperature cable

$\alpha_{\text {concrete }}$ - Thermal expansion coefficient of concrete

ATD - Above tunnel datum $(100 \mathrm{~m}$ ATD $=0$ m OD (Newlyn $))$

bgl - Below ground level

BOTDR - Brillouin optical time-domain reflectometry

$\mathrm{BM}$ - Bending moment

DFOS - Distributed fibre optic sensors

EI - Flexural stiffness of the wall

$\Delta \varepsilon_{\mathrm{B}}-$ Differential mechanically induced strain

$\Delta \varepsilon_{\mathrm{T}, \mathrm{B}}-$ Differential combined temperature and mechanically induced strain

$\Delta \varepsilon_{\mathrm{T}}-$ Differential temperature-induced strain

$\Delta \varepsilon_{\mathrm{TR}}-$ Differential temperature-induced raw strain
$\Delta \mathrm{T}$ - differential temperature

$\mathrm{i}$ - subscript denoting the internal face of shaft

L - Length

$\kappa$ - Curvature

o - subscript denoting the external face of shaft

TBM - Tunnel boring machine

$\mathrm{d}$ - Distance between the strain cables on the internal and external face of the shaft

\section{Introduction}

Field monitoring has the potential to provide considerable cost savings for infrastructure projects. The measurements can be used to assess the construction work in "real time", evaluate existing or new design practices and enable the long-term performance of a structure to be examined. This information is beneficial to assess when maintenance repairs are needed or whether a structure's design life can be extended.

Over the last six years, the Centre for Smart Infrastructure and Construction (CSIC) at the University of Cambridge has developed the use of distributed fibre optic sensors (DFOS) to successfully monitor a range of geotechnical infrastructure 
including slopes, embankments, concrete piles, retaining walls, and tunnels (Kechavarzi et al. (2016)). These sensors can produce accurate, precise readings while being sufficiently robust and durable to withstand the typical harsh construction environment.

Construction of a new Elizabeth Line railway in London provided an invaluable opportunity to embed the DFOS system within four diaphragm wall structures at Pudding Mill Lane portal, Limmo Peninsula tunnel boring machine (TBM) launch shaft, Stepney Green step-plate junction and Paddington station box (Li et al., 2018). The work was carried out under a collaborative Knowledge Transfer Partnership between the University of Cambridge and Crossrail Limited. Such field monitoring is timely as only Schwamb et al. (2014) have monitored strains in a diaphragm wall shaft lining using DFOS before then.

Monitoring of propped rectangular shafts have been widely reported in the literature, possibly due to this type of structure being used as basements and station boxes which are located within close vicinity to residential areas. Early studies by Goldberg et al (1976) and Clough and O'Rourke (1990) reported smaller adjacent ground movements in "weak soils" when diaphragm walls were used compared with sheet pile and soldier pile walls. More recently, Tan and Wang (2015b) reported $80 \mathrm{~mm}$ horizontal ground movement due to excavation of a $17.85 \mathrm{~m}$ deep, $100 \mathrm{~m}$ wide rectangular shaft, which was supported by propped diaphragm walls.

A small number of published studies relate to field monitoring of circular diaphragm wall shafts using strain gauges or inclinometers, which give discrete measurements e.g. Anagnostopoulos and Georgiadis (2002), Cabarkapa et al (2003), Parashar et al. (2007), Tan and Wang (2015a). Where numerical parametric studies have been undertaken it is often cited that the results were not validated against actual field behaviour (Sideri (2012), Zdravkovic et al. (2005)).

The DFOS technology and its application to monitor the development of bending strain during excavation in two diaphragm wall shafts linings at Limmo Peninsula and Stepney Green in east London for the Elizabeth Line is presented in this paper. Such detailed field observations cannot be obtained from conventional monitoring instruments and demonstrate the benefits of using fibre optic sensors to improve our understanding of the actual performance of diaphragm walled shafts.

\section{Fibre optic sensing}

\subsection{Overview}

The theory of DFOS and its successful application for civil infrastructure monitoring has been widely reported e.g. Soga and Luo (2018), Kechavarzi et al. (2016), Soga et al (2015), Soga (2014), Mohamad (2008). Essentially, a power supply, also called an analyser, transmits a pulse of light through an optical fibre cable. The majority of the light signal is conveyed through the fibre and a small amount, the Brillouin component, is reflected back to the analyser. In the frequency domain, the amplitude of the backscattered light exhibits a peak at some constant value of Brillouin frequency. When the optical fibres are strained, due to movement of the diaphragm wall panels or temperature changes, there is a shift in the Brillouin frequency at which this peak amplitude occurs. This Brillouin frequency shift is proportional to strain and temperature.

\subsection{Distributed fibre optic sensors}

Two types of DFOS cables were secured to the reinforcement of the diaphragm wall panels. The first cable was the Fujikura reinforced ribbon cable, to measure combined mechanical and thermal induced strains. The second cable was the Excel eightcore single mode fibre to measure thermal induced strains (Excel OS1 8C 9/125 $\mu \mathrm{m}$ loose tube optical fibre cable). Fibres in the temperature cable were surrounded by a liquid gel and therefore not affected by mechanically induced strains.

During excavation of the shafts, the top internal face of the diaphragm wall was progressively exposed while the bottom part remained embedded in the ground. To capture the mechanically induced strain due to excavation only, the temperature cable was installed alongside the Fujikura reinforced ribbon cable, on both sides of the diaphragm wall panel. This allowed the thermal-induced strains to be easily discounted from the combined mechanically and temperature induced strain.

\subsection{Previous applications for diaphragm walls}

A similar DFOS system was successfully installed in the $1.2 \mathrm{~m}$ thick and $84 \mathrm{~m}$ long diaphragm wall panels supporting Thames Water's Abbey Mills Shaft in east London, UK Schwamb et al. (2014). The observed hoop and longitudinal bending strain measurements during shaft excavation were reported to be larger than the design predictions. The details are given in Schwamb and Soga (2015).

\section{The Elizabeth Line}

\subsection{Project overview}

Crossrail Limited delivered a new $118 \mathrm{~km}$ east-west railway in the UK that is due to open in 2019, the Elizabeth Line. Figure 1 shows a plan view of the route, which connects London with Reading and Heathrow in the west and Shenfield and Abbey Wood in the east.

The $21 \mathrm{~km}$ twin-tunnelled section beneath London comprises new $6.2 \mathrm{~m}$ diameter tunnels, located at depths of up to $40 \mathrm{~m}$ below ground level (bgl). Several large shafts were built to provide access for equipment and personnel to the tunnel horizon and to facilitate spoil removal. Some shafts also provided ventilation and emergency access to the completed tunnels. 
Figure 1 Plan view of London's new Elizabeth Line

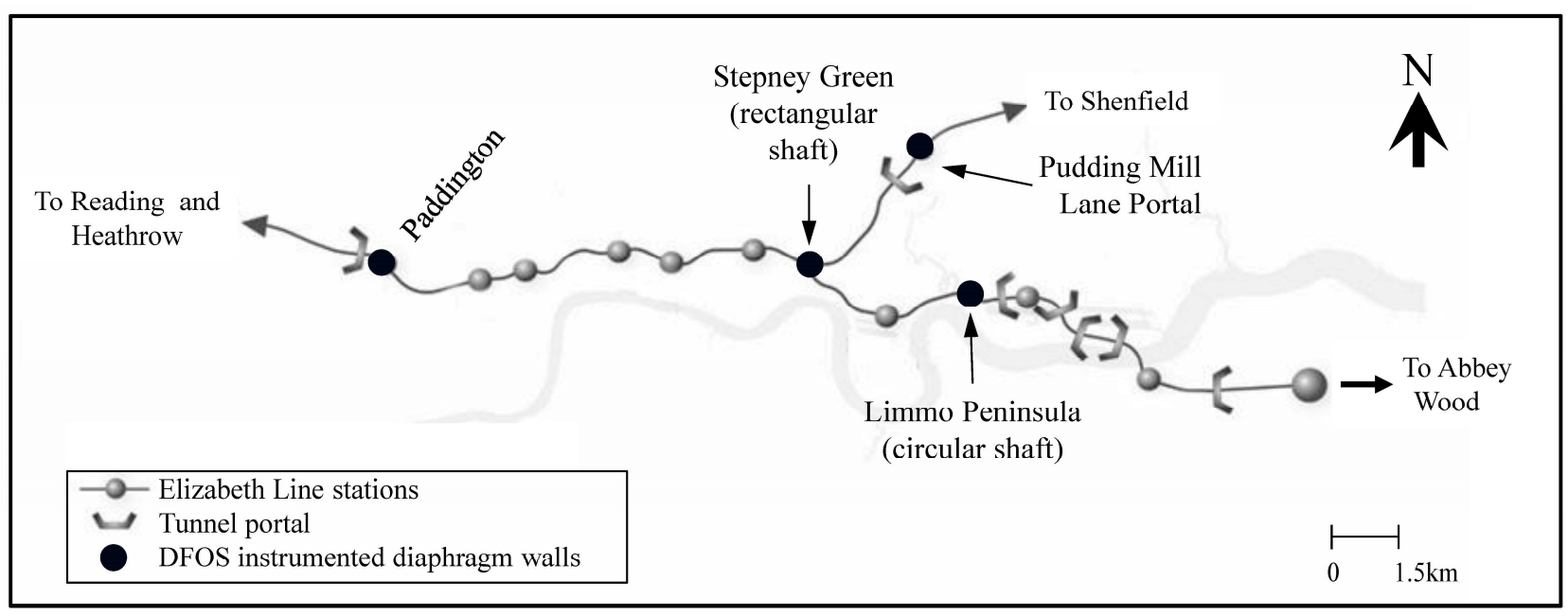

\subsection{Case study shafts}

The DFOS system was embedded in the heavily reinforced diaphragm wall panels of the Limmo Peninsula and Stepney Green shafts to monitor bending of the shaft lining during excavation. The location of both case study shafts is shown in Figure 1.

The circular shaft at Limmo Peninsula was built to launch the Elizabeth Line TBMs. The roughly rectangular $36 \mathrm{~m}$ deep shaft at Stepney Green was built to facilitate construction of large caverns that enable the new railway to divide into a northeast spur towards Shenfield and a southeast spur towards Abbey Wood. The Stepney Green shaft will also house plant and machinery for the completed railway, provide ventilation to the underlying tunnels and serve as an emergency exit.

\subsection{Typical ground and groundwater conditions}

The ground conditions at both shaft sites were typical of the London Basin strata. It consisted of Made Ground and Superficial Deposits (Alluvium and River Terrace Deposits) overlying stiff relatively homogeneous London Clay. The highly variable Lambeth Group, Thanet Sand Formation and Chalk underlie the London Clay.

There are two aquifers at the shaft sites, a shallow aquifer in the Superficial Deposits and a deep aquifer in the lower permeable units of the Lambeth Group, Thanet Sand and Chalk.

At Limmo Peninsula extensive dewatering was carried out (Faustin et al. (2018)) and at Stepney Green, groundwater levels were controlled using depressurisation wells. Details of these groundwater control measures are outside the scope of this paper.

\subsection{Instrumentation of diaphragm wall panels}

For safety reasons, the optical fibre cables were cut to the desired length, labelled in $10 \mathrm{~m}$ intervals and coiled onto a spool before being transported to site.

Individual prefabricated steel reinforcement cages for both shafts were $8 \mathrm{~m}$ to $10 \mathrm{~m}$ long (these were joined together as they were lowered into the excavated slurry-filled trench). On site, the DFOS cables were initially secured along the length of the base reinforcement cage for selected diaphragm wall panels, on both the internal (excavation side) and external (soil side) faces, as shown in Figure 2. An unstrained $10 \mathrm{~m}$ loop of each cable was secured to the bottom of the base reinforcement cage to serve as a reference point for subsequent analysis of the measurements.

Excess optical fibre cables remained coiled onto their respective spool, which was temporarily tied to the top of the reinforcement cage, ready to be secured to overlying cages when they were lowered into the trench. Figure 3 shows a photo of a typical instrumented reinforcement cage and Figure 4 shows the lowering of an instrumented reinforcement cage into an excavated diaphragm wall panel.

DFOS cables exiting the top of the completed diaphragm wall panel were routed to a safe place where strain readings were taken during excavation of the shaft. An initial reading was taken at least 28 days after the diaphragm wall panel was constructed i.e. a reference reading. Subsequent readings were taken at regular intervals, typically every $3 \mathrm{~m}$ excavation. These readings were taken using a Brillouin optical time domain reflectometry (BOTDR) analyser manufactured by Yokogawa (AQ8603 BOTDR). This analyser used the spontaneous Brillouin scattering of the light signal to provide strain values every $5 \mathrm{~cm}$ at a resolution of 30 microstrain (30 $\mu \varepsilon)$ with a spatial resolution of $1.0 \mathrm{~m}$ (Yokogawa (2005)). 
Figure 2 Typical DFOS installation

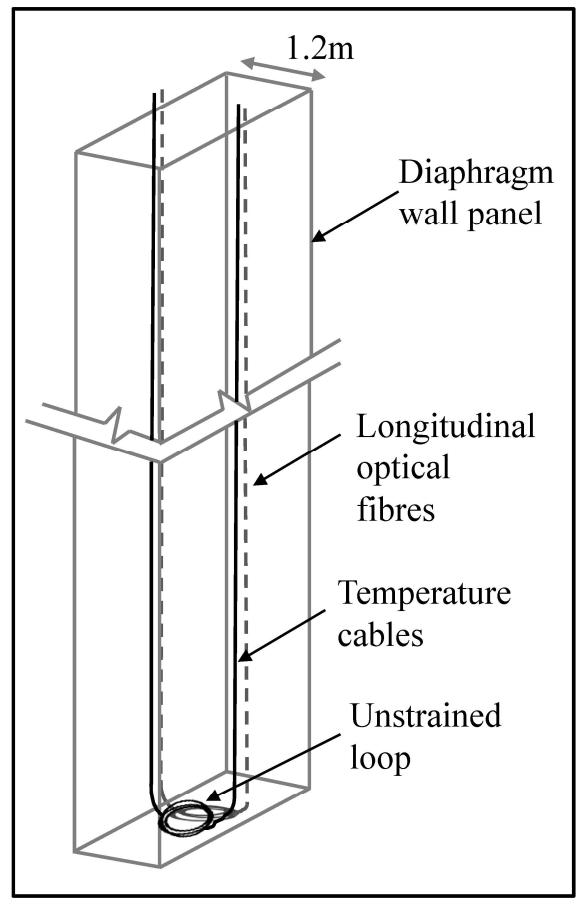

Figure 3 Instrumented bottom reinforcement cage

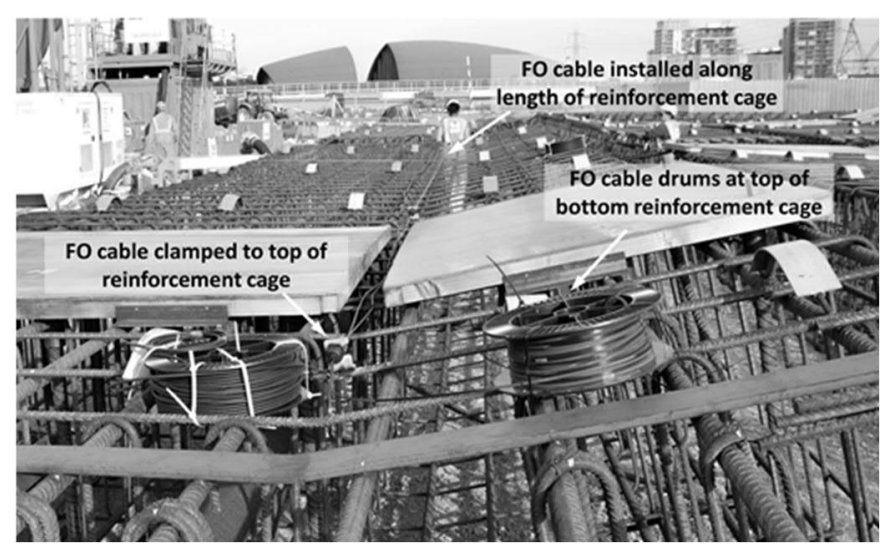

\subsection{Strain measurement interpretation}

Strain measurements for a given shaft excavation depth are presented relative to an initial reference reading taken at the start of excavation i.e. differential strains. Compensation for temperature effects is carried out using Equation (1) to obtain the differential mechanically induced strain $\left(\Delta \varepsilon_{\mathrm{B}}\right)$ due to excavation of the shaft only.

$\Delta \varepsilon_{B}=\Delta \varepsilon_{T, B}-\Delta \varepsilon_{T}$

where $\Delta \varepsilon_{\mathrm{T}, \mathrm{B}}$ is the differential combined temperature and mechanically induced strain, measured by Fujikura reinforced ribbon cable, and $\Delta \varepsilon_{\mathrm{T}}$ is the differential temperature-induced strain. The $\Delta \varepsilon_{\mathrm{T}}$ parameter was derived from the differential temperature-induced raw strain measured by the temperature cable $\left(\Delta \varepsilon_{\mathrm{TR}}\right)$ using Equations (2) and (3):

$\Delta \varepsilon_{T}=\left(\alpha_{\text {concrete }}+\alpha_{\alpha}\right) \Delta T$ where $\alpha_{\text {concrete }}$ is the thermal expansion of the concrete (10 $\left.\mu \varepsilon /{ }^{\circ} \mathrm{C}\right), \alpha_{\alpha}$ is the temperature-induced apparent strain of Brillouin frequency shift $\left(19.47 \mu \varepsilon /{ }^{\circ} \mathrm{C}\right)$ and $\Delta \mathrm{T}$ is the temperature change at either side of the diaphragm wall, calculated using Equation (3)

$\Delta \mathrm{T}=\Delta \varepsilon_{T R} /\left(\alpha_{b}+\alpha_{\alpha}\right)$

where $\Delta \varepsilon_{\mathrm{TR}}$ is the differential temperature-induced raw strain measured from temperature cable and $\alpha_{b}$ is the thermal expansion coefficient of the temperature cable $\left(4.2 \mu \varepsilon /{ }^{\circ} \mathrm{C}\right)$. Further details of this temperature compensation are reported by Mohamad (2008).

Equation (4) was used to derive the change in curvature from the mechanically induced strain measurements obtained on the external and internal faces of the instrumented panel

$\Delta \kappa=\left(\Delta \varepsilon_{B o}-\Delta \varepsilon_{B i}\right) / d$

where $\Delta \varepsilon_{\mathrm{Bo}}$ and $\Delta \varepsilon_{\mathrm{Bi}}$ are the differential mechanically induced strains on the external and internal surface of the shaft respectively and $\mathrm{d}$ is the distance between the bending strain sensing cables on the external and internal side of an instrumented panel. Positive curvature values indicate bending towards the excavation i.e. tension on the external surface and compression on the internal surface of the diaphragm wall panels. The change in curvature is related to a corresponding change in bending moment via the flexural stiffness of the diaphragm wall (EI):

$\Delta \mathrm{BM}=\Delta \kappa \mathrm{KI}$

Figure 4 Installation of instrumented reinforcement cage

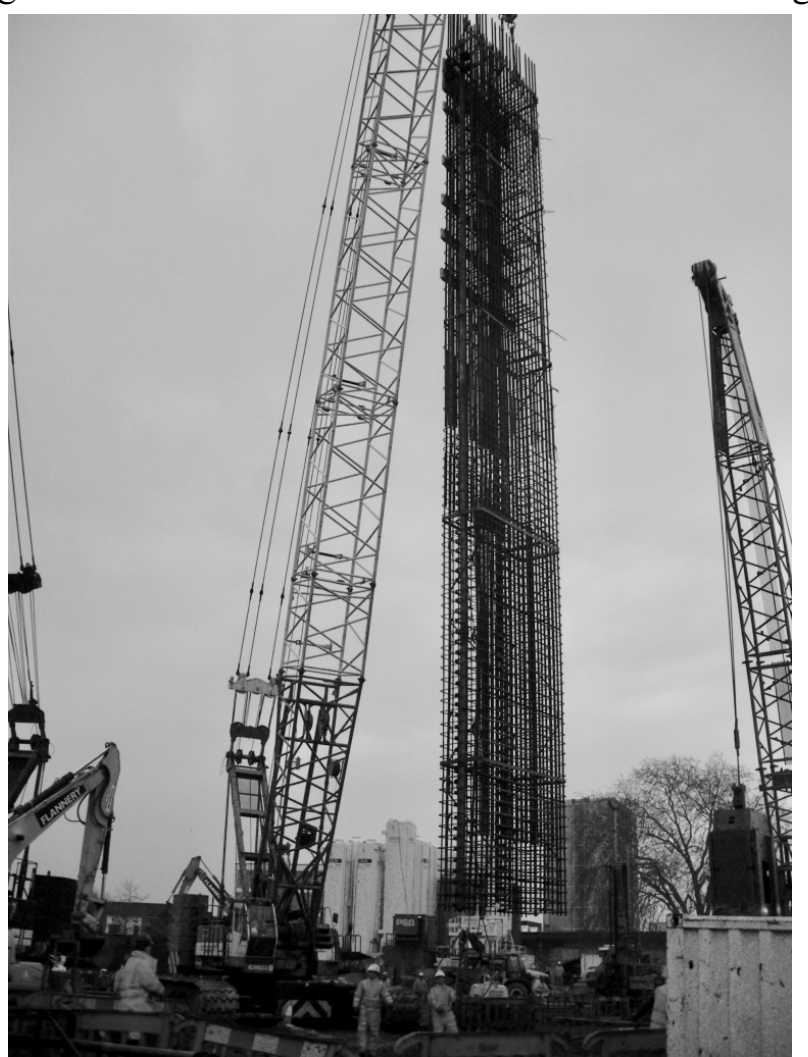




\section{Case Study 1: circular shaft excavation}

\subsection{Limmo Peninsula shaft}

Construction of the $30 \mathrm{~m}$ diameter and $44 \mathrm{~m}$ deep TBM launch shaft at Limmo Peninsula involved two phases. The first phase, carried between October 2011 and January 2012, was the construction of fourteen $1.2 \mathrm{~m}$ thick heavily reinforced diaphragm wall panels. The panels were installed in a circular arrangement and extended $53 \mathrm{~m}$ below ground level, as shown in Figure 5. Five pairs of $1.1 \mathrm{~m}$ thick and $10 \mathrm{~m}$ long steel reinforcement cages were installed in each diaphragm wall panel.

The top $2 \mathrm{~m}$ of the diaphragm wall was subsequently cut and replaced with a $2 \mathrm{~m}$ thick capping beam, to support surface loads from the crane and heavy equipment used to excavate the shaft.

The second phase, excavation of the shaft, was carried out between February and May 2012. The shaft was initially excavated to $39 \mathrm{~m}$ depth. Preparatory works to break out the tunnel eyes were then carried out before excavating the shaft to formation level. The final shaft depth was $44 \mathrm{~m}$ bgl.

Figure 5 Typical profile of the Limmo Peninsula shaft

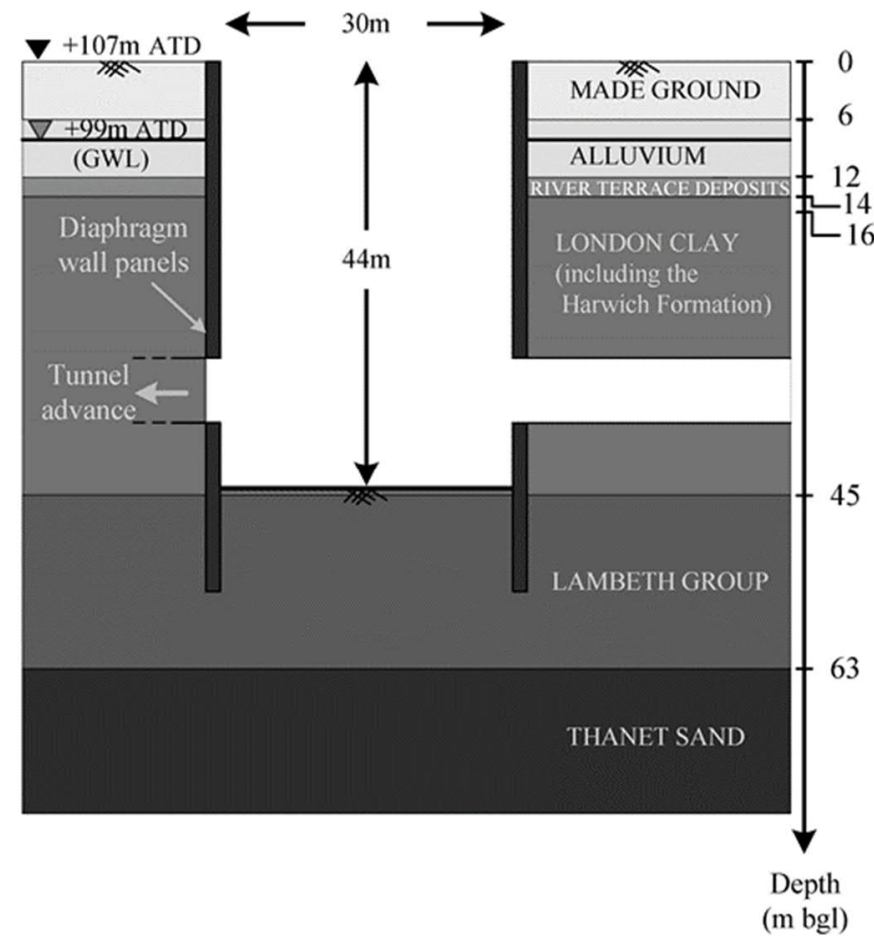

\subsection{Installation of DFOS system}

The DFOS system was installed in three diaphragm wall panels of the Limmo Peninsula shaft, Panels 04, 08 and 13 as shown in Figure 6 and described earlier. A fourth panel was also instrumented but the cables were destroyed while the reinforcement cages were lowered into the excavated trench.

The DFOS system was secured to the reinforcement using Lshaped brackets and a clamp, as described by Schwamb et al. (2014). The brackets were welded onto the $32 \mathrm{~mm}$ thick reinforcing bars at regular at intervals along the length of the reinforcement cages. The Fujikura reinforced ribbon cable was later attached to the brackets using a bespoke clamp. This clamp was also used to apply pre-tension to the cables (approximately 1500 to 2000 microstrain); this helped with subsequent processing of the measurements.

The temperature cable was tied directly to the steel reinforcing bars, alongside the Fujikura reinforced ribbon cable, using cable ties. No pretension was applied to the temperature cable.

\subsection{Site constraints}

The installation and monitoring procedure for the DFOS system was as described earlier with some modification to accommodate the contractor's construction sequence. Firstly, wooden panels were placed across the internal surface of the reinforcement cages at the ring beam and base slab locations. The wooden panels were due to be removed after the diaphragm wall panel was cast, thereby reducing the amount of concrete break-out required to construct the ring beam and base slab. There was a great risk of the optical fibre cables in this zone may be damaged in the process. Therefore, a $10 \mathrm{~mm}$ diameter reinforcement bar was welded along the $40 \mathrm{~mm}$ wide gap between the wooden panels and the optical fibre cables were secured to this without any tension applied in this zone (see Figure 3).

Secondly, the fibre optical cables were routed through a $0.1 \mathrm{~m}$ diameter and $3 \mathrm{~m}$ long steel pipe at the top of the panel to protect them during construction of the capping beam.

Thirdly, the DFOS system could not be commissioned until the excavation of the shaft was about to start due to heavy equipment and plant congestion on the site as well as safety concerns. Three days' notice was given but the BOTDR analyser was not available and the DFOS system was commissioned when the shaft excavation depth was $13.5 \mathrm{~m} \mathrm{bgl}$. Subsequent measurements were taken at $3 \mathrm{~m}$ intervals. Therefore, strain measurements are presented relative to an excavation depth of $13.5 \mathrm{~m} \mathrm{bgl}$.

\section{4 Bending strain measurements}

Longitudinal bending strains observed in the three panels were similar and typical data for Panel 4 is presented in this paper.

Figure 7 shows the combined temperature and mechanically induced strain $\left(\Delta \varepsilon_{\mathrm{T}, \mathrm{B}}\right)$ and the temperature-induced strain $\left(\Delta \varepsilon_{\mathrm{T}}\right)$ in the diaphragm wall Panel 4 at two excavation depths, 18.9 $\mathrm{m}$ and $33.5 \mathrm{~m}$. Measurements are shown relative to the initial reference reading for both the internal and external face of the shaft. The combined temperature and mechanically induced strain are seen to be marginally greater than the strain due to temperature changes. This indicates that most of the strain arises from temperature changes when the internal face of the shaft is exposed during excavation i.e. there is little strain due to mechanical effects i.e. displacement of the shaft lining. 
Figure 6 Plan view of the Limmo Peninsula shaft

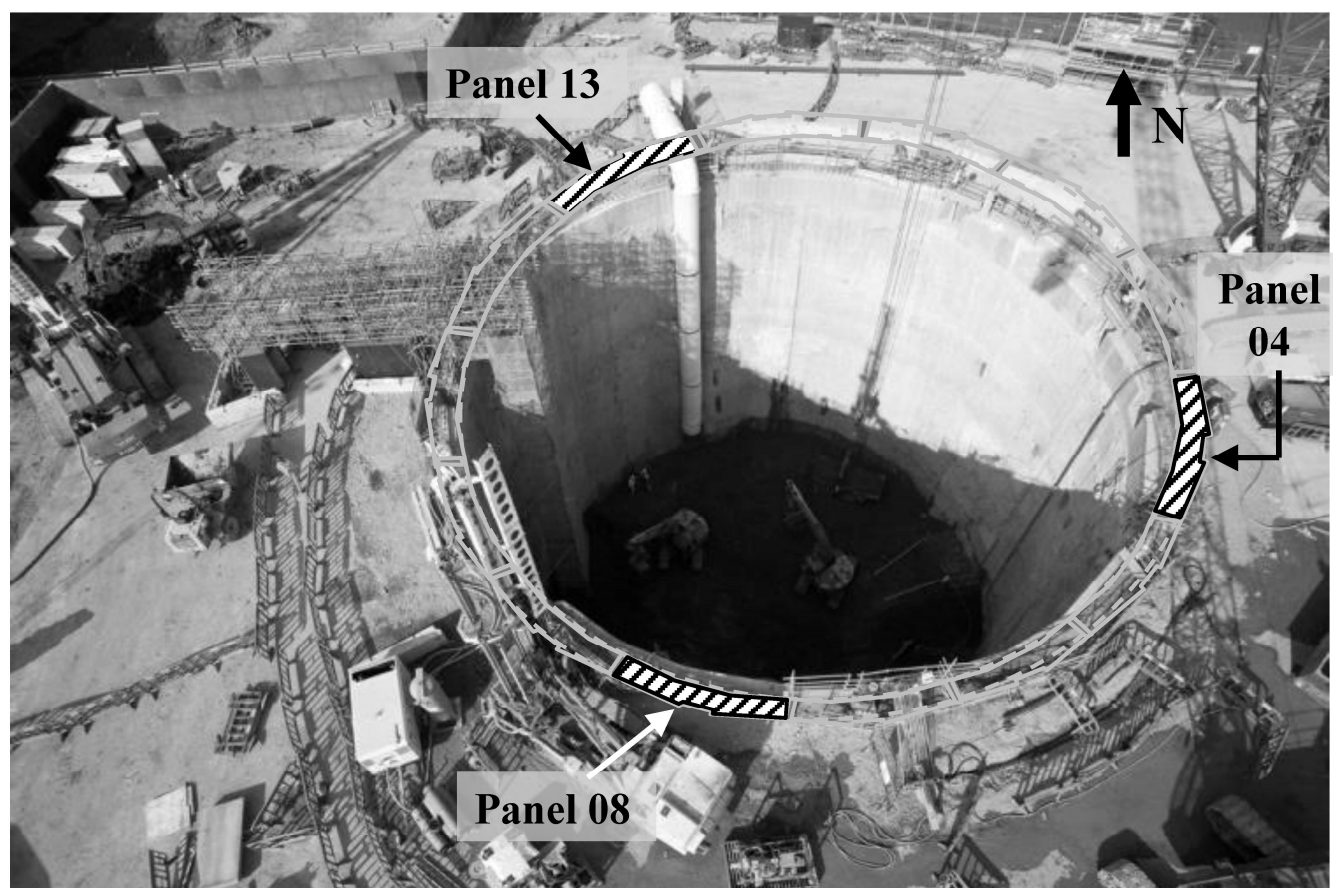

Figure 7 Observed strains in Panel 4 during excavation

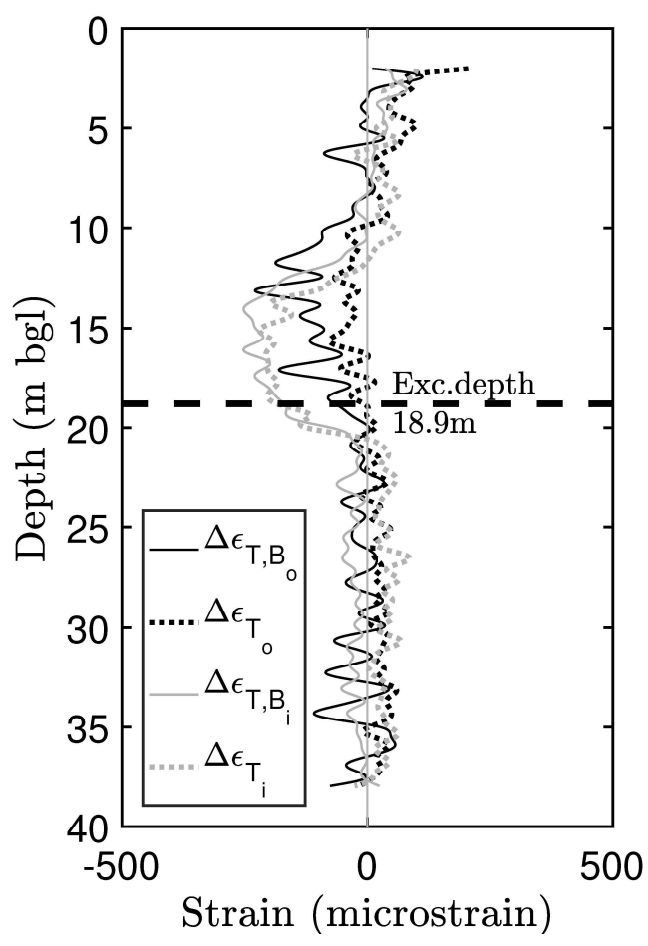

Figure 7 also shows that the change in temperature due to excavation is not uniform across the diaphragm wall panel; the temperature-induced strains are approximately 200 microstrain greater on the internal face of shaft which is exposed during excavation. This corresponds to a temperature difference of approximately 8.5 degrees Celsius, based on Equation (3). Below the excavation level, the strains are similar on both the internal and external face of the shaft lining.

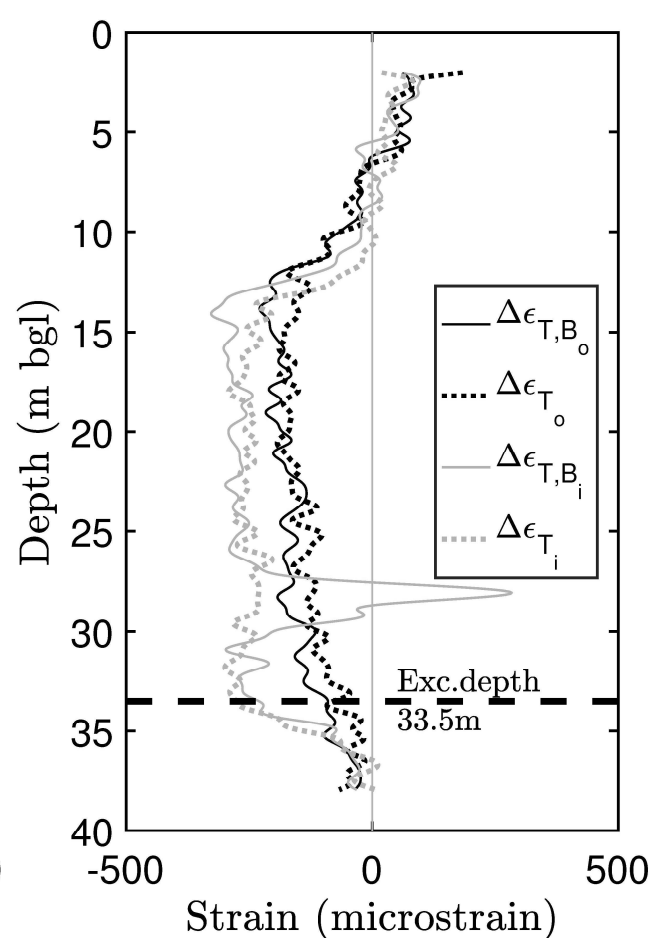

Figure 8 shows that the diaphragm wall panels experience very little bending, taking into consideration that the baseline strain was taken at an excavation depth of $13.5 \mathrm{~m} \mathrm{bgl}$ and not at the start of excavation. The curvature values are rather small in both directions suggesting that the measurements are mainly due to noise and that there is little or no bending of the $1.2 \mathrm{~m}$ thick diaphragm wall panel. 
Figure 8 Derived curvature in Panel 4 during excavation

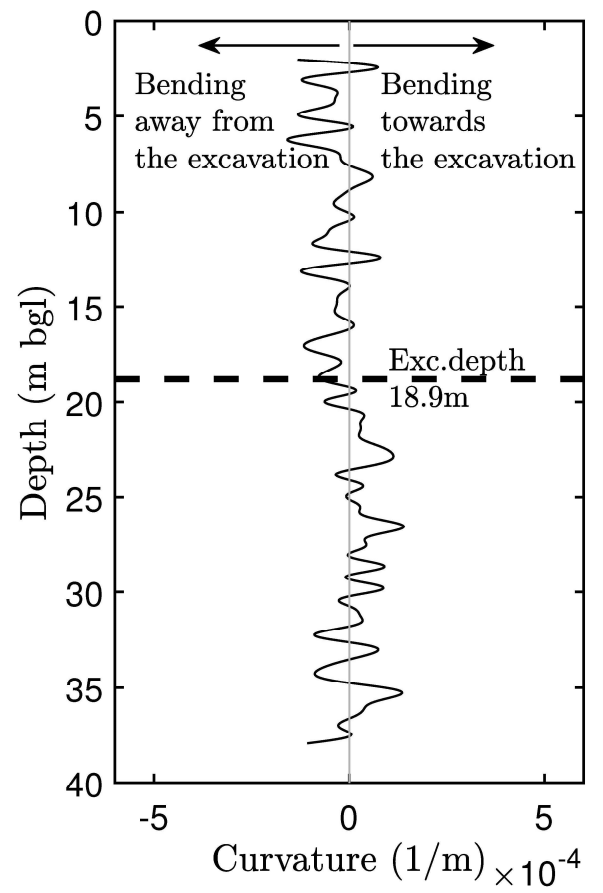

A maximum absolute change in curvature of $1.4 \times 10^{-4}$ per metre, measured at an excavation depth of $33.5 \mathrm{~m} \mathrm{bgl}$ (ignoring the extreme peak) gives a corresponding change in bending moment of $452 \mathrm{kN} \mathrm{m} \mathrm{m}-1$ using Equation (5) and a value of 19.6 GPa for the Young's modulus of concrete, E.

\section{Case Study 2: rectangular shaft excavation}

\subsection{Stepney Green cross-over cavern}

The roughly rectangular Stepney Green shaft is approximately $65 \mathrm{~m}$ in length and has a variable width of $16 \mathrm{~m}$ to $18 \mathrm{~m}$. The shaft lining comprises 24 diaphragm wall panels, each being $1.2 \mathrm{~m}$ thick and $48 \mathrm{~m}$ deep. A plan view and typical profile of the Stepney Green shaft are shown in Figure 9 and Figure 10 respectively.

The shaft box was excavated using a top-down construction; the deepest section of the shaft was excavated to $36 \mathrm{~m}$ bgl to accommodate the westbound tunnel, and the other section to $30 \mathrm{~m} \mathrm{bgl}$ to accommodate the eastbound tunnel. The diaphragm wall shaft lining was supported by $1 \mathrm{~m}$ thick cast in-situ reinforced concrete props and walers that were incorporated into the permanent basement floors. The props were designed to resist lateral earth pressures in the temporary and permanent conditions.

Temporary props were also constructed at lower levels within the Stepney Green shaft to provide bracing around the tunnel openings until the base slab was constructed. A series of openings were left in the centre of the basement floor slabs to facilitate plant and material movement during the construction phase (Figure 9).

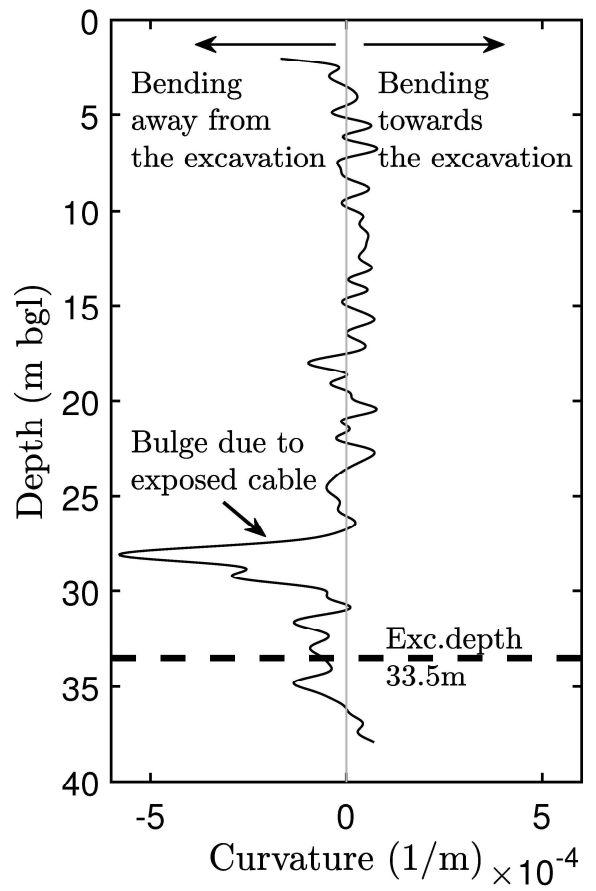

\subsection{Installation details}

The DFOS system was installed in five diaphragm wall panels, labelled 2, 4, 8, 9 and 10 on Figure 9. The cables were installed to monitor bending strains and temperature variations along the depth of the panels. The cables were installed along the full depth of the wall except for Panels 2 and 9 where the DFOS cables extended from the top of the panel to just above the crown of the underlying sprayed concrete lined tunnel.

Multiple steel reinforcement cages were installed in the excavated trenches and the installation procedure was similar to that described earlier. However, Araldite glue was used to attach the Fujikura reinforced ribbon cable to the reinforcement cage, instead of the bespoke metal bracket and clamp adopted at the Limmo Peninsula shaft site. The optical fibre cables were temporarily clamped to the steel reinforcement bars, under a pretension of 1500 to 2500 microstrain, before being secured with glue at several points. Gluing the cables directly onto the reinforcement bar provided extra protection and reduced the risk of breakage during subsequent construction of the diaphragm wall panel.

At the top of the reinforcement cage the cables were routed through a slotted steel pipe (50 mm diameter and $4.5 \mathrm{~m}$ long) that extended about $0.5 \mathrm{~m}$ below the wooden "box out" for the basement roof. Since the cables were routed through a single pipe, the measurements obtained from the top $6 \mathrm{~m}$ of the wall will be omitted when the results are presented.

Measurements from the shallow installation at Panel 9 will be presented in this paper. DFOS cables were secured to the top reinforcement cage only. Panel 9 was installed on $19^{\text {th }}$ January 2012 and subsequent readings showed that the cables 
Figure 9 Plan view of the Stepney Green shaft

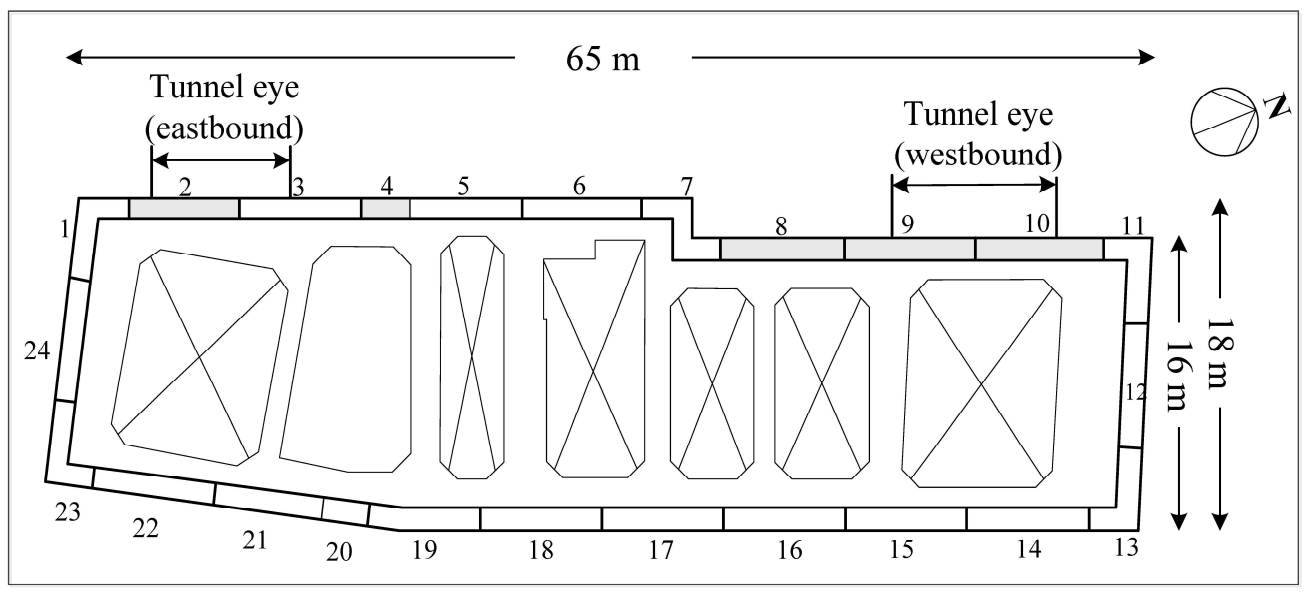

were intact after the cage was placed in the trench. Due to site constraints and availability of the BOTDR analyser, a reference reading was taken on $12^{\text {th }}$ March 2012, when the shaft excavation depth was $3 \mathrm{~m}$ bgl. Therefore, DFOS measurements are presented in this paper relative to an excavation depth of $3 \mathrm{~m}$ bgl.

\subsection{Fibre optic measurements at Stepney Green}

Figure 11 shows the differential combined strains $\left(\Delta \varepsilon_{\mathrm{B}}\right)$ and differential temperature-induced strains $\left(\Delta \varepsilon_{\mathrm{T}}\right)$. Measurements from the internal and external face of the shaft at different excavation levels are presented.

A drop in the differential temperature-induced strains on the internal $\left(\Delta \varepsilon_{\mathrm{Ti}}\right)$ and external $\left(\Delta \varepsilon_{\mathrm{To}}\right)$ face of the shaft is observed during excavation. The maximum change in the strain is approximately 200 microstrain on the internal face of the shaft, which corresponds to an 8.5 degrees Celsius decrease in temperature. Figure 11 shows that the differential temperatureinduced strains are more pronounced on the internal face of the wall which is exposed during excavation, compared with the external face which is insulated by the $1.2 \mathrm{~m}$ thick shaft lining. Below the excavation level, the shaft lining is less affected by temperature changes. Liou (1999) and Kumagai et al. (1999) explain that this behaviour arises because the heat convective loss from exposure to air is greater than the heat conductive loss from exposure to the surrounding ground. The measurements in Figure 11(b) and (c) were taken 2 weeks apart and it can be seen that by this time, the difference in temperature on each side of the wall started to equalise. This is due to transmission of temperature from the exposed face through the diaphragm wall panel with time.

Figure 11 also shows a similar trend for the differential combined strains $\left(\Delta \varepsilon_{\mathrm{T}, \mathrm{Bo}}\right.$ and $\left.\Delta \varepsilon_{\mathrm{T}, \mathrm{Bi}}\right)$; there is a greater reduction in strain at the internal face of the wall $\left(\Delta \varepsilon_{\mathrm{T}, \mathrm{Bi}}\right)$ compared with the external face $\left(\Delta \varepsilon_{\mathrm{T}, \mathrm{Bo}}\right)$. This suggests that the internal face of the shaft lining compresses as the excavation progresses i.e. the shaft lining bends towards the excavation. There is minimal change below the excavation level. When a prop is cast, a peak is observed at the propped level, on the internal face of the shaft only, indicating that the internal face of the shaft lining is under tension at this very specific point (Figure $11(\mathrm{c})$ ).

As observed at the Limmo Peninsula shaft, the differential combined strain profiles and the differential temperatureinduced strain profiles are similar. This suggests that the behaviour of the structure is more affected by temperature changes rather than mechanical changes due to deformation i.e. there is minimal displacement of the rectangular shaft lining due to excavation.

Bending moments were derived from the strain measurements using Equation (5). The maximum and minimum envelopes from all the readings, taken at a given depth, are presented in Figure 12. Design envelopes from numerical analyses supplied by the contractor are also shown. Derived bending moments were much smaller than the numerical predictions due to the minimal change in mechanically induced strain caused by displacement due to excavation of the shaft.

Figure 10 Typical profile of the Stepney Green shaft

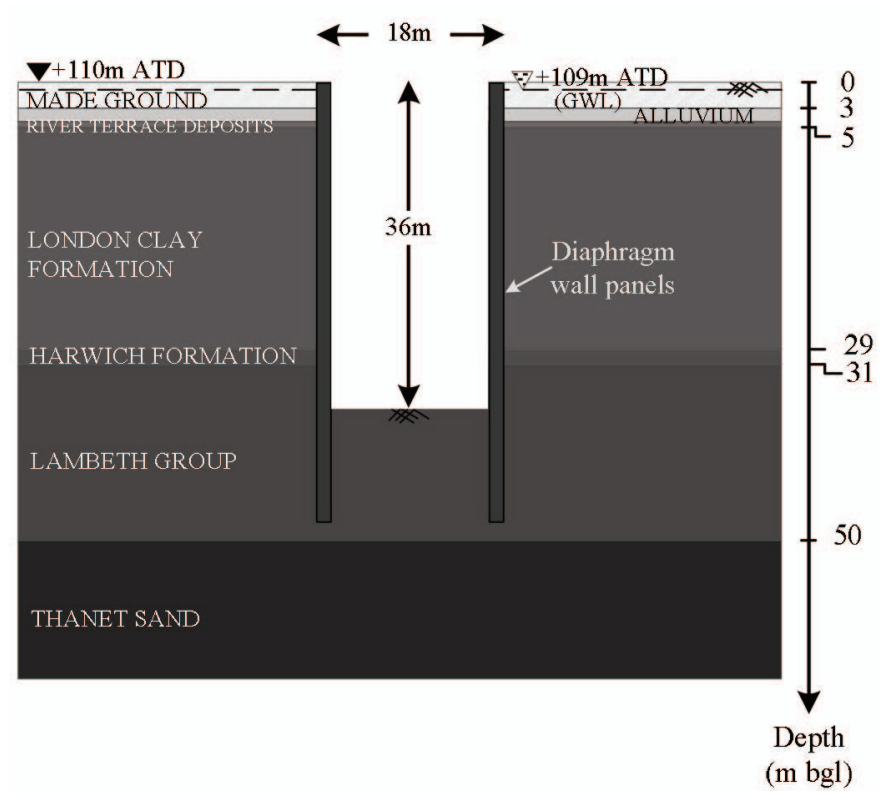


Figure 11 Measured differential strains - Stepney Green

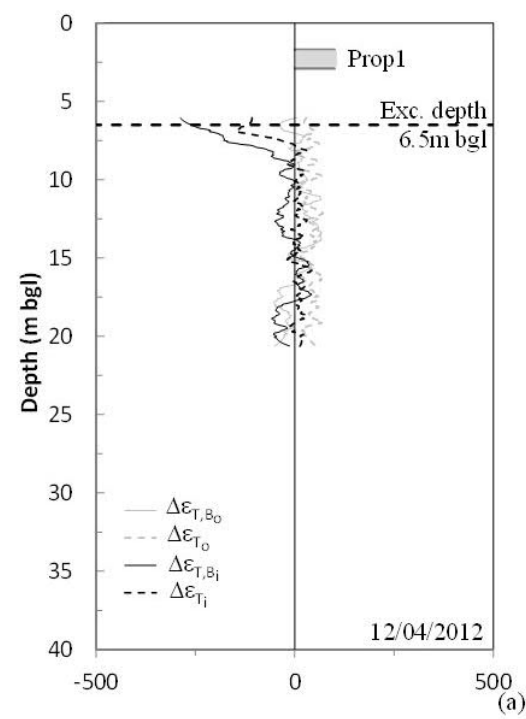

\section{Comparison of measurements at both sites}

Although the case study shafts had different geometries, similar behaviour was observed during excavation. The dominant effect of temperature on the behaviour of the shaft lining compared with the excavation-induced strains was evident. The small amount of mechanically induced strain during excavation caused minimal bending of the heavily reinforced rectangular and circular shaft linings.

The same amplitude of temperature strain, 200 microstrain, was observed at both shaft sites when the internal shaft wall was exposed during excavation. Both shaft linings were $1.2 \mathrm{~m}$ thick and the strain readings at each site were taken on similar days.

\section{Conclusions}

In this paper monitoring of two diaphragm wall shafts, one circular and one rectangular, using DFOS is described. The DFOS system survived the harsh construction environment and provided insight into the mechanical and temperature strains induced in diaphragm wall shaft linings during excavation.

During excavation of both the rectangular and circular shafts, the combined mechanically and temperature induced strains were observed to be similar to the temperature-induced strains derived from the temperature cable. This indicates that the mechanically induced strain is considerably smaller than the temperature-induced strain.

The DFOS system embedded in the rectangular shaft at Stepney Green also captured the effect on the shaft lining when the internal prop supports were installed. Multiple conventional monitoring instruments would be required to

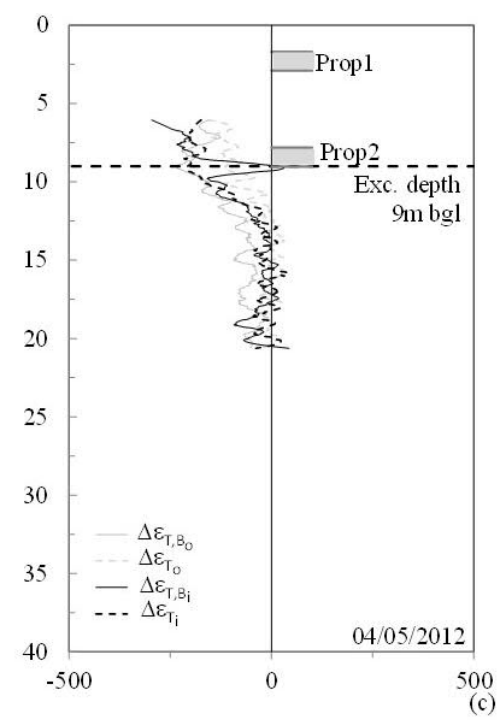

identify similar behaviour, which is costly and has the added complexity of positioning the sensors at the right location.

The derived bending moments have been much smaller than assumed in the design. However, based on the fibre optic monitoring data, bending by thermal difference across the shaft lining is greater than bending due to displacement caused by excavation and the dominant effect of temperature changes should be accounted for in the design of future shaft linings. These findings show that fibre optic monitoring has an important role to play in performance-based design - in optimising and improving future designs.

\section{Acknowledgements}

The authors would like to thank the Innovate UK (formerly the Technology Strategy Board) and Crossrail Limited for funding this research. They also express gratitude to Crossrail Limited for permission to publish the field data and site photographs. The support of Carillion, Costain and Cementation Skanska is also gratefully acknowledged. In addition, special thanks are given to Dr Chang Ye Gue, Dr. Fei Wang, Koson Janmonta, Masanari Nakashima, Mohamad Alserdare, Peter Knott, Dr Phil Smith, Dr Tina Schwamb, Thomas Smith and Dr Yue Ouyang. This research would not have been possible without their help and support with the fieldwork. 
Figure 12 Stepney Green bending moment

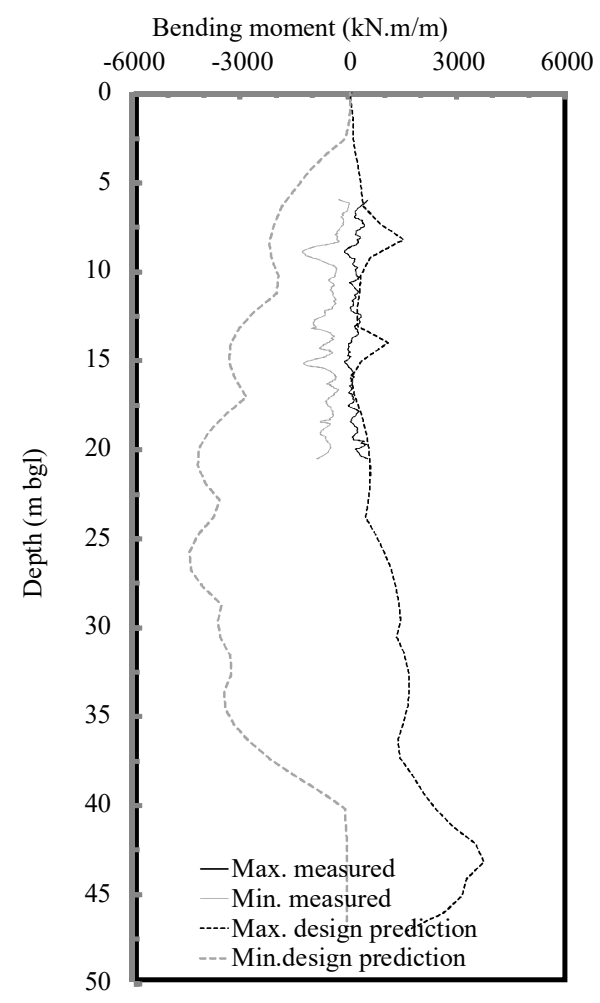

\section{References}

Anagnostopoulos C and Georgiadis K (2002) Behaviour of an instrumented circular diaphragm wall. Proc 15th ICSMGE Istanbul, (6):1061-1064.

Cabarkapa Z et al. (2003) Design and performance of a large diameter shaft in Dublin boulder Clay. In Proceedings of Foundations: Innovations, Observations, Design and Practice (Newson TA (ed.)), 10.1680/fiodap.32446.0017.

Clough G and O'Rourke T (1990) Construction induced movements of in situ wall. Design and Performance of Earth Retaining Structures, ASCE Geotechnical Special Publication 25: 439-470.

Faustin NE et al. (2017) Field measurements of ground movements associated with circular shaft construction. In: 9th International Symposium on Geotechnical Aspects of Underground Construction in Soft Ground, pp. 301-308.

Goldberg DT et al. (1976) Lateral Support Systems and Underpinning. US Federal Highway Administration, Washington, DC, USA, Report FHWA-RD-75-128, Vol.1.

Kechavarzi C et al (2016) Distributed fibre optic strain sensing for monitoring civil infrastructure: A practical guide. ICE Publishing, London, UK, 10.1680/dfossmci.60555.bm.

Kumagai T et al. (1999) Behaviour and Analysis of a Largescale Cylindrical Earth Retaining Structure. Soils and Foundations 39(3):13-26 https://doi.org/10.3208/sandf.39.3_13.
Li Z et al. (2018) Distributed fibre optic sensing of a deep excavation adjacent to pre-existing tunnels. Géotechnique Letters 8(3): 171-177, https://doi.org/10.1680/jgele.18.00031.

Liou D (1999) Thermal Effects in Large-Sized Diaphragm Wall. Journal of Performance of Construction Facilities, 13(1): $\quad 17-21, \quad$ https://doi.org/10.1061/(ASCE)08873828(1999)13:1(17).

Mohamad H (2008) Distributed Optical Fibre Strain Sensing of Geotechnical Structures. PhD thesis, Cambridge University, Cambridge, UK.

Parashar S et al. (2007) Performance monitoring of deep shafts at Changi WRP project, Singapore. In 7th Int. Symp. on Field Measurements in Geomechanics (FMGM 2007). Geotech. Spec. Publ. 175 (GSP175), ASCE, Reston, VA, https://doi.org/10.1061/40940(307)15.

Schwamb T and Soga K (2015) Numerical Modelling of a Deep Circular Excavation at Abbey Mills in London. Géotechnique, 65(7): 604-619, https://doi: 10.1680/geot.14.P.251.

Schwamb T et al. (2014) Fibre optic monitoring of a deep circular excavation. Proceedings of the Institution of Civil Engineers - Geotechnical Engineering 167(2): 144-154, https://doi.org/10.1680/geng.13.00036.

Sideri M (2012) A study of ground loading on shafts. Master's dissertation, Imperial College, London, UK.

Soga K (2014) XII Croce Lecture: Understanding the real performance of geotechnical structures using an innovative fibre optic distributed strain measurement technology, Rivista Italiana di Geotecnica, vol 4, pp. 7-48.

Soga $\mathrm{K}$ et al. (2015) The role of distributed sensing in understanding the engineering performance of geotechnical structures. Proceedings of the XVI European Conference on Soil Mechanics and Geotechnical Engineering, Edinburgh, 10.1680/ecsmge.60678.vol1.002.

Soga K and Linqing L (2018) Distributed fiber optics sensors for civil engineering infrastructure sensing. Journal of Structural Integrity and Maintenance, 3:1, 1-21, 10.1080/24705314.2018.1426138.

Tan Y and Wang D (2015a) Structural Behaviors of Large Underground Earth-Retaining Systems in Shanghai. I: Unpropped Circular Diaphragm Wall. Journal of Performance of Constructed Facilities, 29(2): 04014058. https://doi.org/10.1061/(ASCE)CF.1943-5509.0000521.

Tan Y and Wang D (2015b) Structural Behaviors of Large Underground Earth-Retaining Systems in Shanghai. II: Multipropped Rectangular Diaphragm Wall. Journal of Performance of Constructed Facilities, 29(2): 04014059. https://doi.org/10.1061/(ASCE)CF.1943-5509.0000535.

Yokogawa (2005) AQ8603 Optical Fiber Strain Analyzer http://cdn.tmi.yokogawa.com/files/uploaded/buaq8603_00e_1 .pdf (accessed 10/01/2019).

Zdravkovic L et al. (2005) Modelling of a 3D excavation in finite element analysis. Géotechnique, 55(7): 497-513, https://doi.org/10.1680/geot.2005.55.7.497. 